\title{
PÂNICO, PERSONALIDADE FÓBICA, DESAMPARO E MASOQUISMO: ARTICULAÇÕES PSICANALÍTICAS
}

\author{
Eloisa Serpa Zanetti* \\ Rodrigo Sanches Peres**
}

\section{Resumo}

Neste estudo apresentaremos uma leitura psicanalítica do pânico fundamentada em três operadores conceituais: personalidade fóbica, desamparo e masoquismo. Propostos por autores nacionais que têm prestado importantes contribuições para a compreensão dessa modalidade de sofrimento psíquico, os referidos operadores foram selecionados por se alinharem à perspectiva da dimensão subjetiva. Para isto, empregaremos material clínico de uma paciente que preenchia os critérios diagnósticos para transtorno de pânico. À luz desse material, o pânico será enquadrado entre as psicopatologias da atualidade. Além disso, serão discutidos aspectos psicopatológicos centrais dessa modalidade de sofrimento psíquico, salientando sua natureza multifacetada.

Palavras-chave: pânico; psicanálise; psicoterapia; psicologia clínica.

\begin{abstract}
PANIC, PHOBIC PERSONALITY, HELPLESSNESS AND MASOCHISM: PSYCHOANALYTIC DISCUSSIONS

This study present a psychoanalytical view of panic based on three conceptual operators: phobic personality, helplessness and masochism. Proposed by Brazilian authors who have been giving important contributions to the understanding of this kind of psychological suffering, the cited conceptual operators were selected because were aligned to the subjective dimension
\end{abstract}

* Psicóloga, especialista em Psicoterapias de Orientação Psicanalítica pela Universidade Federal de São Carlos.

** Psicólogo; Mestre e doutor em Psicologia pela Universidade de São Paulo; Especialista em Psicologia Clínica pelo Conselho Federal de Psicologia; Professor adjunto do Instituto de Psicologia da Universidade Federal de Uberlândia. 
perspective. Also we will use clinical material from one patient with panic disorder diagnostic as illustrative resource. We will consider the panic among the contemporary psychopathologies. Thus, we will discuss central psychopathology aspects of this kind of psychological suffering accentuating its multifaceted nature.

Keywords: panic; psychoanalysis, psychotherapy, clinical psychology.

\section{INTRODUÇÃO}

Freud afirmou que:

não é de esperar que o uso da palavra "pânico" seja claro e determinado sem ambiguidade. Às vezes ela é utilizada para descrever qualquer medo coletivo, outras até mesmo para descrever o medo no indivíduo quando ele excede todos os limites e, com frequência, a palavra parece reservada para os casos em que a irrupção do medo não é justificada pela ocasião ([1921] 1996: 108).

Essa clássica passagem da literatura psicanalítica ilustra com clareza que a complexidade do pânico - modalidade de sofrimento psíquico popularizada na atualidade através dos modernos sistemas diagnósticos em psicopatologia - é conhecida há tempos.

Nardi (2006), em um estudo sobre a história da categoria nosográfica atualmente chamada de transtorno de pânico, aponta que a mesma foi objeto de diversas tentativas de compreensão ao longo do tempo. $\mathrm{Na}$ Antiguidade, devido a relatos literários e folclóricos, o pânico era considerado um fenômeno sobrenatural por egípcios e assírios. Durante a Idade Média e o Renascimento, o pânico passou a ser associado à depressão e, ao longo do século XIX, à ansiedade. A mudança da abordagem médica para a abordagem psicológica da ansiedade engendrou novos paradigmas diagnósticos para a moderna psiquiatria. Entretanto, esse processo não impediu que o pânico fosse examinado, até a primeira metade do século XX, essencialmente a partir de uma perspectiva biológica.

Em um interessante estudo sobre a natureza polissêmica da palavra "pânico", Pereira (1996a) aponta que sua etimologia remete não apenas às crises, que, conforme a tradição grega, seriam provocadas pelo perturbador deus Pã, mas também, de acordo com a perspectiva aristotélica, à totalidade que se caracteriza pelo acúmulo de elementos indiferentes entre si e se opõe à totalidade estruturada decorrente da harmonia entre as partes e o todo. Somam-se a estes diversos outros significados que podem ser atribuídos à palavra "pânico". Por isso, o autor salienta, ainda, que é surpreendente sua permanência nos sistemas diagnósticos que clas- 
sificam os transtornos mentais a partir de uma linguagem comum para clínicos e pesquisadores das mais distintas orientaçôes teóricas.

Deve-se destacar que foi em 1980, com a publicação da terceira edição do Manual Diagnóstico e Estatístico de Transtornos Mentais, que a categoria nosográfica "transtorno de pânico" foi criada. Com poucas inovações, a edição mais recente dessa mesma publicação caracteriza tal categoria basicamente em função da presença de ataques de pânico recorrentes e inesperados. Estes promovem intenso desconforto, não estão associados a um ativador situacional e desencadeiam sintomas somáticos e cognitivos como: palpitações, sudorese e tremores ou desrealização, despersonalização e medo de perder o controle e "enlouquecer", dentre outros. Além disso, precipitam preocupação persistente acerca da possibilidade de um novo ataque ou alterações comportamentais relacionadas (American Psychiatric Association [APA], 2003).

Outro sistema diagnóstico vigente nos dias de hoje e igualmente inspirado em uma abordagem operacional e empírica também admite a categoria nosográfica "transtorno de pânico" e a compreende essencialmente da mesma forma. Observa-se, na seção de descrições clínicas de transtornos mentais e de comportamento da Classificação Internacional de Doenças (CID-10), em sua décima edição, que a categoria referida tem como aspecto central ataques recorrentes de pânico com sintomas graves de ansiedade que, por não serem restritos a qualquer situação ou conjunto de circunstâncias em particular, têm a imprevisibilidade como marca. Além disso, frequentemente são seguidos pelo medo de um novo ataque (Organização Mundial de Saúde [OMS], 1993).

Diversos autores - tais como Pereira (1996b) e Dalgalarrondo (2000) - defendem que os sistemas diagnósticos, embora tenham proporcionado avanços importantes tanto para a prática quanto para a pesquisa em psiquiatria, não são capazes de exprimir a condição do paciente em sua natureza multifacetada, já que se pautam apenas em manifestações sintomáticas diretamente observáveis. Consequentemente, tendem a promover um reducionismo de modalidades de sofrimento psíquico mais complexas, das quais o pânico pode ser considerado um bom exemplo. Em certa medida, os próprios sistemas diagnósticos admitem essas limitações, pois abertamente propóem um acordo pragmático, destituído de referências, às diversas escolas teóricas capazes de enriquecer o debate psicopatológico.

A partir do que foi exposto, neste estudo apresentaremos uma leitura psicanalítica do pânico fundamentada em três operadores conceituais, a saber: personalidade fóbica, desamparo e masoquismo. Estes têm sido propostos por autores nacionais que têm prestado importantes contribuiçōes para a compreensão dessa modalidade de sofrimento psíquico em suas diversas nuances: Trinca (1997), Pereira 
(2003) e Menezes (2005). Estes operadores conceituais foram selecionados por se alinharem à perspectiva da dimensão subjetiva. Assim, se prestam ao delineamento de alguns aspectos psicopatológicos do pânico atrelados a elementos de natureza emocional. Além disso, vale destacar que empregaremos material clínico referente a uma paciente que preenchia os critérios diagnósticos para transtorno de pânico ${ }^{1}$ como recurso ilustrativo.

A pertinência do assunto ora abordado se torna patente tendo-se em vista que o pânico é considerado por muitos autores - Birman (2001), Garcia e Coutinho (2004), dentre outros - uma modalidade de sofrimento psíquico cuja frequência crescente pode ser associada à predominância de certos valores típicos da contemporaneidade. Já a escolha teórico-metodológica que norteia o presente estudo se justifica pelos fatores explicitados a seguir.

Em primeiro lugar, pois, como pode revelar um rápido levantamento bibliográfico em qualquer base de dados científica, o conhecimento produzido acerca do pânico se encontra demasiadamente atrelado à abordagem operacional e empírica adotada pelos sistemas diagnósticos. Ou, ainda, à concepção biologizante que impera na psiquiatria contemporânea e muitas vezes hiperdimensiona seus componentes orgânicos e genéticos.

Em segundo lugar, a psicanálise, conforme seu fundador, constitui um procedimento para a investigação dos processos mentais profundos. E seu método consiste, basicamente, em explorar o significado das produçôes do inconsciente (Freud, [1923] 1996). Em função disso, Eizirik (2007) sustenta que a psicanálise foi e continuará sendo:

uma das ciências básicas da psiquiatria, ou seja, uma das disciplinas que fundamentam a compreensão do funcionamento psíquico normal, das diferentes expressões da psicopatologia e dos meios através dos quais a ação terapêutica de nossas diferentes intervenções pode ter efeitos positivos, inócuos ou iatrogênicos (Eizirik, 2007: 15).

Ou seja, a psicanálise ainda tem importantes contribuições a prestar ao debate psicopatológico. Contudo, há que se reconhecer que o diálogo entre psicanálise e psiquiatria pressupõe uma relação de complementaridade e não de oposição. Tal ressalva se faz necessária para que possam ser contornadas antigas polêmicas que conduzem a impasses ideológicos contraproducentes. Afinal, cumpre assinalar que a psicanálise, como qualquer ciência, depende da produção de conhecimento para continuar se renovando. $\mathrm{O}$ autor supracitado a concebeu como uma obra em construção. Além disso, defendeu que a descoberta de possibilidades de intercâm- 
bio com outros saberes - dentre os quais a história, a filosofia, a antropologia e a até mesmo a psiquiatria - é um dos maiores desafios que a atualidade lhe impõe (Eizirik, 2007).

\section{Aspectos Éticos}

Utilizaremos as diretrizes propostas por Goldim e Protas (2007) para a veiculação de material clínico em publicações científicas. Os referidos autores observam que, embora desejável, a obtenção do consentimento de pacientes para tanto é impossível em muitos casos ${ }^{2}$, sobretudo quando a situação de assistência da qual deriva o material não se caracteriza como situação de pesquisa. A veiculação de material clínico pode justificar-se, nesses casos, em função de seus benefícios potenciais para uma determinada classe profissional ou para a população geral. A propósito, vale lembrar que a Resolução 196/96 do Conselho Nacional de Saúde, a qual dispõe sobre os aspectos éticos em pesquisas envolvendo seres humanos, também regulamenta que, em situações excepcionais, a impossibilidade da obtenção do consentimento do paciente não impede a veiculação de material clínico, desde que a identidade do mesmo seja preservada.

\section{Desenvolvimento - Caso Clínico}

Mariana $^{3}, 28$ anos, primogênita de pais separados, solteira, profissional de nível superior, procurou assistência psicológica referindo ataques de ansiedade graves não associados a um ativador situacional específico. Estes ataques eram chamados por ela de "crises", durante as quais ocorriam sintomas psíquicos e físicos tais como: taquicardia, sudorese, despersonalização e medo de perder o controle. Dificuldades para se alimentar em ambiente social e problemas importantes no relacionamento com a família e com o namorado também foram relatados.

Quanto ao seu âmbito familiar, ela descrevia o pai como uma pessoa "difícil de agradar", que sempre lhe exigia o melhor. A mãe era caracterizada por suas atitudes intrusivas e por tratar todos como criança, além de "se fazer de vítima do mundo".

O primeiro operador conceitual a ser discutido será o de personalidade fóbica. Segundo Trinca (1997), pacientes que - a exemplo de Mariana - preenchem os critérios diagnósticos para transtorno de pânico apresentam uma personalidade diferenciada. Sendo seu desenvolvimento marcado por buracos inconscientes no self, resultantes de rupturas, mais ou menos intensas, que se processam no centro de 
sustentação interna da pessoa como tentativas de romper com forças de coesão e de integração que operam no interior do aparelho psíquico. A noção de personalidade fóbica foi concebida pelo autor em questão para fazer referência à estrutura que determina o funcionamento mental desses pacientes. Estrutura esta que os torna especialmente vulneráveis à angústia de dissipação do self.

As seguintes verbalizações ${ }^{4}$ apresentadas por Mariana, em momentos distintos de sua $133^{a}$ sessão, ilustram como a mesma sofria em função de uma preocupação persistente com a possibilidade de novos ataques após a diminuição da dosagem da medicação. Também se nota que a paciente invalidava sua capacidade de controlar as crises em situações menos estruturadas e via seu trabalho como uma espécie de "porto seguro". Possivelmente, isso ocorria devido a um sobreinvestimento fóbico da realidade externa, correlativo de uma suposta incapacidade de dar forma à própria realidade interna. Tais preocupaçōes nos remetem à noção de personalidade fóbica, descrita pelo autor supracitado e que constitui um dos operadores conceituais adotados no presente estudo, já que pode ser considerada um reflexo do temor da dissolução fundamental da noção de si mesmo.

Mariana: "Tem hora que acho que queria ficar só, mas acho bom morar com eles lás, porque assim eles me tiram do meu mundo. [Silêncio] Então, como tá diminuindo o remédio, eu tô sentindo ânsia, vontade de vomitar [...] Como se tivesse algo aqui [Aponta a garganta e o peito]. Com o remédio não estava sentindo isso, tinha parado, agora voltou".

Mariana: "Acho que tô decepcionada comigo mesmo. Tô com muita raiva. [Choro]. Tô chorando de raiva. Acho que agora a responsabilidade é minha de não ter mais crise. Eu fui convidada para ir num casamento em outra cidade. Eu tô querendo muito ir [...]. Mas tô vacilando, tô com medo de ir e ter crise. Se tivesse alguma coisa, uma programação, se fosse trabalho, tudo bem, eu iria numa boa. Mas como é para se divertir, já acho que não vou dar conta de ir".

Parece razoável propor, considerando-se as entrelinhas da primeira verbalização, que Mariana associava certos sintomas físicos apresentados por ela não apenas à diminuição da dosagem da medicação, mas também à convivência com os colegas de trabalho com os quais residia. Afinal, o relacionamento estabelecido com os mesmos, na medida em que a impossibilitava de permanecer apenas "em seu mundo", era vivenciado com ambivalência a seguir: a despeito de qualificado como "bom", representava, em última instância, uma ameaça de desarticulação para seu sentimento de identidade. $\mathrm{O}$ mesmo se poderia cogitar, tendo-se em vista 
a segunda verbalização, sobre sua aproximação com outras pessoas por ocasião do casamento para o qual fora convidada.

Aprofundando esse raciocínio, morar sozinha e não ir ao casamento seriam, para Mariana, tentativas de eliminar a angústia de dissipação do self que a espreitava. Logo, representariam medidas preventivas contra a ocorrência de ataques de pânico, que poderiam resultar da desintegração dos limites da própria realidade interna a partir da implementação de uma condição de indiferenciação em relação ao outro, potencialmente danosa. Trata-se de uma estratégia típica da personalidade fóbica, a qual se encontra diretamente associada a uma extrema dificuldade em se ver como se é. Para Trinca (1997), o indivíduo que se deixa dominar por essa dificuldade aparenta ter reprimido o prazer de viver, até porque deixa de apreender uma série de nuances e matizes de suas experiências.

Em suma, devido ao enfraquecimento do self, há um distanciamento intrapsíquico que tende ao esvaziamento do ser e pode ensejar o pânico. Ambos os fenômenos acarretam um sofrimento emocional intenso e devem ser considerados psicopatológicos, na medida em que rompem o canal de comunicação que deveria se manter entre as instâncias do aparelho mental. Essas conclusões gerais podem ser subentendidas a partir da descrição da noção de personalidade fóbica e vislumbradas a partir do material clínico em questão ${ }^{6}$. Como sustenta Trinca (1997: 59), "estando impossibilitado de dar forma ao mundo interno e de usar os seus recursos para dominar as emoções, o paciente fica ao capricho da indeterminação e da imprevisibilidade, bem como das ameaças de ódio e de destrutividade".

Em sua 139ª sessão traz novas verbalizações referentes ao segundo operador conceitual proposto neste estudo: desamparo. Mariana, já sem namorado, falou sobre a possibilidade de viajar para sua cidade de origem de carona com um colega de trabalho, com o qual estava tentando flertar. Aventar essa possibilidade lhe despertava grande insegurança, como se observa a partir da verbalização que segue abaixo. É possível constatar que, para a paciente, ficar dentro do carro de um homem, com o qual poderia ter algum envolvimento amoroso, significava o irrompimento de incertezas e indefiniçóes; estas, por sua vez, capazes de colocar por terra sua organização psíquica. Logo, parece razoável propor que Mariana temia a ocorrência de um ataque de pânico na situação em questão, pois a iminência da viagem era vivenciada como uma ameaça concreta de inundamento pulsional.

Mariana: "Vou viajar nesse fim de semana e eu sei que poderia ir de carona com o Carlos, mas não sei se estou preparada. [Silêncio] Ele vai mais tarde porque sai mais tarde do trabalho. Eu teria que esperá-lo porque saio mais cedo. Mas não sei se estou preparada para ir com ele. Ficar dentro do carro, inventar as- 
sunto... E se me der uma crise, não vou ter pra onde ir. Mas também era uma oportunidade de se conhecer. Eu posso não ir, eu sempre fui sozinha mais cedo [...]. Como também posso ir com ele. Seria uma oportunidade de ver o que vai acontecer, sabe? Se vai ter crise ou não...”.

Esta verbalização nos remete à noção de desamparo, como dito um outro operador conceitual. Suas entrelinhas sugerem que um eventual ataque de pânico durante a viagem poderia ser entendido como um indício de que o aparelho psíquico da paciente era capaz de produzir apenas angústias automáticas, e não sinais de angústias, ao se deparar com estímulos potencialmente desestruturantes. Afinal, para Freud ([1926] 1996), as angústias automáticas são experimentadas passivamente pelo ego como a expressão de descargas vegetativas de emergência. Ao passo que os sinais de angústia remetem a uma situação anterior de excitação, devidamente controlada quando da experiência original, produzindo uma espécie de contracatexia. Esta, por sua vez, indica para o ego a necessidade de se fazer valer de um movimento protetor.

Logo, a situação abordada por Mariana em sua verbalização sinaliza sua preocupação com a possibilidade da instauração de um estado de falência de seu funcionamento psíquico. Como bem observa Pereira (2003), é justamente esse estado que, em termos freudianos, recebe o nome de desamparo. Além de protótipo da situação traumática geradora de angústia para o adulto, o desamparo se encontra associado à condição de prematuração do ser humano. E, consequentemente, à dependência do bebê em relação à mãe, devido à impotência do mesmo para satisfazer suas próprias necessidades mediante a realização de ações capazes de colocar fim às suas tensões internas (Freud, [1926] 1996).

Porém Pereira (2003) sustenta que o pânico constitui o último esforço envidado pelo aparelho psíquico na tentativa de evitar o aniquilamento de sua organização. Seguindo esse raciocínio, trata-se, então, de um ato psíquico pleno, ainda que desesperado, e não apenas de uma pura descarga. Desse modo, o referido autor afirma que “o pânico não remete ao desamparo 'primitivo' do bebê, mas coloca em evidência a dimensão de desamparo profundo sobre a qual se desenvolve em última instância, todos os processos do aparelho psíquico” (Pereira, 2003: 246). Ou seja, o pânico pode ser entendido como uma espécie de descarga, dotada de uma potência de linguagem, capaz de inscrevê-lo em uma história pessoal a partir do momento que confere forma à memória filogenética que é intrínseca à angústia automática.

O terceiro operador conceitual - masoquismo - começa a ser visto em sua $142^{\mathrm{a}}$ sessão, na qual Mariana relatou o sofrimento oriundo de pressões sociais e 
pessoais, as quais estabelecem ideais que a mesma vivenciava como inatingíveis. Nessas circunstâncias, não raro o vínculo libidinal, que liga o ego ao ideal do ego, se rompe. Menezes (2005) sustenta que o pânico resulta justamente desse rompimento, uma vez que leva o indivíduo a oscilar à deriva entre os polos do narcisismo e da alteridade, ensejando, como consequência, a instalação de uma situação de desestruturação interna iminente. Logo, pode-se cogitar que Mariana, não dispondo tanto do amor de si quanto do amor do outro até então, carecia de um suporte para assegurar a organização de seu universo simbólico.

Mariana: "Eu tive uma crise em casa, não sei se é por causa do trabalho. Tinha falado para os chefes que eu estava estressada, cansada, não estava aguentando, estava precisando de férias [...]. Aí, eu fui para casa e mandei uma mensagem para o Carlos, o paquera, falei para ele passar em casa quando chegasse. Ele respondeu que, se desse, ele passaria. Aí, depois... Não sei se foi isso, eu comecei a ter uma crise dentro de casa, isso nunca aconteceu antes. Então, no dia seguinte, cheguei a ir ao trabalho, mas não consegui trabalhar. Fui embora mais cedo, tomei o Rivotril e não lembro mais nada. Também tem o Renato que saiu de casa essa semana para morar com a namorada, que tá grávida, e o quarto dele tá vazio, não sei quem vai entrar ali, se vai entrar alguém. Não sei se tem a ver com coisa de casal".

Saliente-se que, para Menezes (2005), o rompimento com o ideal do ego, observado em muitos casos de pânico, não implica no rompimento com o superego, visto que o primeiro pode ser considerado, em termos freudianos, uma espécie de subestrutura do segundo. A referida autora esclarece que se processa, na realidade, uma acentuação da vertente sádica e cruel do superego, o que impede o indivíduo de funcionar conforme as regras do princípio do prazer. $\mathrm{O}$ ego, assim, se submete ao superego, instituindo uma modalidade de funcionamento psíquico que desconsidera o desejo e a singularidade. Submeter-se a algo ou alguém capaz de tornar a própria existência tolerável é, nessas circunstâncias, uma medida compreensível, ainda que desesperada.

Durante o período em que a sessão em questão foi realizada, Mariana utilizava a medicação com o intuito de proteger-se do confronto com seu desamparo. Partindo desse princípio, é possível inferir que a mesma ocupava uma posição de assujeitamento. Tal inferência nos remete à noção de masoquismo, o último operador conceitual adotado no presente estudo. Afinal, segundo Menezes (2005: 203), "no pânico está em jogo o masoquismo como figura de servidão". A referida autora esclarece que isso não quer dizer que o indivíduo sente prazer com a dor, mas sim abre mão de sua liberdade em troca de uma segurança ilusória. Ou seja, 
entendendo o masoquismo em um sentido mais amplo, torna-se claro que Mariana buscava na medicação um refúgio para escapar do terrível vazio que sentia - simbolicamente representado pelo quarto vago em sua verbalização apresentada - em relação à sua própria vida.

Entretanto, a busca de refúgios dessa natureza é escravizante. Mariana inclusive o atestou ao colocar-se em uma condição de servidão masoquista. Justamente por essa razão, a incerteza acerca do comportamento de Carlos - iria ele visitá-la ou não - mencionada na verbalização de Mariana teve um efeito tão devastador para a mesma que ensejou a ocorrência de mais uma "crise". É nesse sentido que Menezes (2005) sustenta que a servidão leva o indivíduo a não arriscar o imprevisível, isto é, a não se aventurar na experiência da castração. Conclui-se, portanto, que o masoquismo associado ao pânico pode ser caracterizado como primário, já que remete a um estado em que a pulsão de morte ainda é dirigida ao próprio sujeito.

\section{Discussão}

Menezes (2005) salienta que os valores soberanos na atualidade incitam a utilização do polo do narcisismo no processo de constituição da subjetividade, o que conduz à redução do homem à dimensão da imagem. Isso potencializa o desencontro entre as exigências sociais e as capacidades individuais. Mas confrontar-se com as próprias fragilidades é entendido, à luz da ideologia predominante na cultura contemporânea, essencialmente como um fracasso. Desenvolvendo esse raciocínio, a referida autora defende que o pânico, enquanto reação à vivência de tal fracasso - extrema a ponto de ensejar a servidão masoquista como contrapartida a uma proteção supostamente onipotente -, pode ser considerado o efeito de um processo de produção social.

Sendo assim, é possível enquadrar o pânico entre as chamadas psicopatologias da atualidade, ou seja, entre as modalidades de sofrimento psíquico típicas de nossa época (Birman, 2001). Como mencionado anteriormente, o pânico foi objeto de diversas tentativas de compreensão através do tempo. Portanto, sua relação com a contemporaneidade não implica em ineditismo. Considerar o pânico uma das psicopatologias da atualidade resulta, em última instância, do reconhecimento de que o mesmo, tendo sua incidência incentivada pelo estilo de vida característico dos dias de hoje, pode ser entendido como uma nova configuração do mal-estar da civilização.

Para Garcia e Coutinho (2004: 127), essa nova configuração do mal-estar da civilização decorre essencialmente da "promessa enganosa de obtenção da li- 
berdade e do prazer irrestrito". Logo, na atualidade - em contraste com o período vitoriano, durante o qual as consequências subjetivas das restriçôes à satisfação das pulsões eram prevalentes -, a prática clínica permite a identificação dos efeitos psíquicos da imposição de uma busca ilimitada do prazer. Nesse cenário, o excesso pulsional muitas vezes é vivido como angústia, de modo que o culto à liberdade individual estimula a constante busca por satisfação e, paradoxalmente, leva a experiências de fracasso.

Situar o pânico no contexto dos modos de subjetivação promovidos pela sociedade contemporânea reforça, a nosso ver, sua associação com a personalidade fóbica. Ocorre que, como mencionado anteriormente, Trinca (1997) salienta que a mesma, devido à existência de "buracos" inconscientes no self, conduz à impossibilidade de moldar a própria realidade interna. E a cultura atual cria uma conjuntura potencialmente favorável para o surgimento desses buracos levando-se em consideração que, para Peres e Justo (2000), a economia globalizada instituiu o provisório como modo de existência, tornando, assim, cada vez mais superficiais os relacionamentos afetivos e mais instáveis as fixações sociais.

Consubstanciando essa linha de raciocínio, Mendes e Paravidini (2007) defendem que a globalização implementou o império do efêmero. Desse modo, o movimento, a fluidez e a flexibilidade passaram a caracterizar a sociedade, o que promoveu a emergência de um discurso individualista diametralmente oposto ao discurso coletivo vigente até então. Os referidos autores defendem, inclusive, que as chamadas psicopatologias da atualidade, a despeito de suas especificidades, podem ser entendidas como um subproduto da falência psíquica do sujeito frente ao mundo idealizado que se produz sob a égide desse fenômeno. Na cultura contemporânea, portanto, o individualismo tem concorrido para a fragilização do indivíduo.

Feita essa breve digressão acerca das implicaçôes de determinadas mudanças sociais em nosso tempo para a organização psíquica na contemporaneidade, parece razoável afirmar que a personalidade fóbica fomenta o hiperdimensionamento da vulnerabilidade às ameaças de desorganização psíquica a que todos, influenciados pelos modos de subjetivação emergentes nos dias de hoje, somos submetidos incontáveis vezes ao longo da vida. E, frente a essa vulnerabilidade hiperdimensionada, medidas drásticas são adotadas - a servidão masoquista seria uma delas - pelo indivíduo com o intuito de evitar a queda em um abismo existencial.

A uma constatação complementar se pode chegar a partir do resgate da noção de desamparo. Pereira (2003) defende que o pânico é a última muralha erguida contra o risco de desorganização emocional, que se vislumbra a partir do contato com o próprio desamparo. Parece razoável, então, propor que os ataques de pânico surgem como respostas radicais a tentativas malogradas de controlar 
ameaças de inundamento pulsional. Assim, em que pese o fato de essas ameaças serem precipitadas essencialmente pela constatação de uma condição estruturante do psiquismo - seu destino a organizar-se, sem garantias, em relação - que não foi simbolizada, o pânico não deixaria de ser uma espécie de pedido de socorro, o que o credencia como algo para além de uma pura descarga.

Mariana pode ser considerada um exemplo disso. A propósito, faz-se necessário esclarecer que, para os fins do presente estudo, optou-se por privilegiar o material clínico oriundo de sessões realizadas em um período no qual manifestações sintomáticas mais subjetivas se sobressaíam em relação às manifestaçôes sintomáticas mais objetivas. Procuramos com isso contornar a abordagem operacional dos sistemas diagnósticos, por um lado, e a concepção biologizante da psiquiatria contemporânea, por outro. Ou seja: buscamos discutir certas condiçôes supostamente associadas aos ataques de pânico de Mariana em seus aspectos psicopatológicos centrais, com o intuito de colocar em relevo a natureza multifacetada dos mesmos e não de descrevê-los à luz da categorização nosográfica.

\section{CONSIDERAÇÕES FINAIS}

A partir da articulação de operadores conceituais propostos por autores nacionais com o material clínico, o presente estudo fornece subsídios para a compreensão, à luz da psicanálise, de alguns aspectos psicopatológicos do pânico. Porém novos estudos são necessários para que essa modalidade de sofrimento psíquico seja compreendida para além dos critérios diagnósticos pautados em manifestaçôes diretamente observáveis. Parece razoável propor até mesmo que a superação dos impasses, frequentemente vivenciados na prática clínica pelos profissionais que se dedicam à abordagem psicanalítica do pânico, depende disso.

\section{REFERÊNCIAS}

American Psychiatric Association. (2003). Manual diagnóstico e estatístico de transtornos mentais IV-TR (C. Dornelles, Trad.). Porto Alegre: Artes Médicas.

Birman, J. (2001). Subjetividades contemporâneas. Psychê, 5 (7), 151-169.

Dalgalarrondo, P. (2000). Psicopatologia e semiologia dos transtornos mentais. Porto Alegre: Artes Médicas.

Eizirik, C. L. (2006). Psychoanalysis as a work in progress. International Journal of Psychoanalysis, 87, 645-650. 
Eizirik, C. L. (2007). A psiquiatria nos próximos 50 anos: a contribuição da psicanálise. Revista de Psiquiatria do Rio Grande do Sul, 29 (1), 15-16.

Freud, S. (1921/1996). Psicologia de grupo e análise do ego. Obras completas, ESB, v. XVIII. Rio de Janeiro: Imago.

Freud, S. (1923/1996). Dois verbetes de enciclopédia. Obras completas, ESB, v. XVIII. Rio de Janeiro: Imago.

Freud, S. (1926/1996). Inibições, sintomas e angústia. Obras completas, ESB, v. XX. Rio de Janeiro: Imago.

Garcia, C. A., \& Coutinho, L. G. (2004). Os novos rumos do individualismo e o desamparo do sujeito contemporâneo. Psychê, 8 (13), 125-140.

Goldim, J. R., \& Protas, J. S. (2007). Aspectos éticos da publicação de relatos de caso em psicoterapia. Revista Brasileira de Psicoterapia, 9 (2), 147-157.

Mendes, E. D., \& Paravidini, J. L. L. (2007). Os significantes da escuta psicanalítica na clínica contemporânea. Psychê, 11 (20), 99-116.

Menezes, L. S. (2005). Pânico e desamparo na atualidade. Ágora, 8 (2), 193-206.

Nardi, A. E. (2006). Some notes on a historical perspective of panic disorder. Jornal Brasileiro de Psiquiatria, 55 (2), 154-160.

Organização Mundial de Saúde. (1993). Classificação de transtornos mentais e de comportamento da Classificação Internacional de Doenças (CID-10): descriçôes clínicas e diretrizes diagnósticas (D. Caetano, Trad.). Porto Alegre: Artes Médicas.

Pereira, M. E. C. (1996a). A palavra pânico ou da polissemia como método. Coletâneas da Associação Nacional de Pesquisa e Pós-Graduação em Psicologia, 16 (1), 55-78.

Pereira, M. E. C. (1996b). Questões preliminares para um debate entre psicanálise e psiquiatria no campo da psicopatologia. Coletâneas da Associação Nacional de Pesquisa e Pós-graduação em Psicologia, 16 (1), 43-53.

Pereira, M. E. C. (2003). Psicopatologia dos ataques de pânico. São Paulo: Escuta.

Peres, R. S., \& Justo, J. S. (2000). Andarilhos de estrada: a vivência do provisório como modo de existência. Revista de Iniciação Cientifica, 2, 431-439.

Trinca, W. (1997). Fobia e pânico em psicanálise. São Paulo: Vetor.

\section{Notas}

1 A paciente foi atendida em psicoterapia de orientação psicanalítica pela primeira autora do presente estudo. Além disso, foi atendida por um psiquiatra, o qual corroborou o diagnóstico e conduziu o tratamento psicofarmacológico.

2 A ideia de utilizar o material clínico referente à paciente em questão para os fins do presente estudo surgiu após o desfecho da psicoterapia. A obtenção de seu consentimento foi impos- 
sibilitada pelo fato de a mesma ter-se mudado de cidade. Ocorre que, com isso, a primeira autora do presente estudo não mais dispôs de canal de comunicação com a paciente.

3 O nome verdadeiro da paciente e das demais pessoas citadas por ela nos relatos apresentados neste estudo foram substituídos por nomes fictícios com o intuito de assegurar-lhes o anonimato.

4 Todas as verbalizaçôes da paciente apresentadas neste estudo resultam de anotaçōes executadas pela primeira autora com a maior fidelidade possível imediatamente após o final das respectivas sessões de psicoterapia.

5 Nessa oportunidade a paciente residia com colegas de trabalho em uma cidade diferente da sua cidade de origem.

6 Vale lembrar que a personalidade fóbica se afigura como uma estrutura que determina o funcionamento mental de muitos pacientes que preenchem os critérios diagnósticos para transtorno de pânico. O material clínico apresentado coloca em relevo apenas algumas dessas dimensões dessa estrutura. Entretanto, optamos por não veicular nesta oportunidade material clínico ilustrativo de outras dimensões em função das limitações de espaço para o presente estudo.

Recebido em 11 de junho de 2009 Aceito para publicação em 4 de abril de 2011 